\title{
Reflectance Confocal Microscopy Applied to Linear (en Coup de Sabre) Morphea
}

\author{
Sara Mazzillia Laura Vollono $^{a}$ Terenzio Cosio $^{a} \quad$ Michele Donati $^{b}$ \\ Arianna Piccolo $^{a}$ Cosimo Di Raimondo ${ }^{a}$ Elena Campione ${ }^{a}$ Luca Bianchi $^{a}$ \\ a Dermatology Unit, Department of "Medicina dei Sistemi," Tor Vergata University, Rome, Italy; \\ ${ }^{b}$ Department of Surgical Pathology, Campus Biomedico, Rome, Italy
}

\section{Established Facts}

- Band-like alopecia represents a condition related to linear scleroderma. The diagnosis of this rare disease is clinically supported.

\section{Novel Insights}

- The use of reflectance confocal microscopy in this scarring hair disorder could represent a helpful therapeutic and diagnostic tool, especially in the early stage of this condition.

\section{Keywords}

Reflectance confocal microscopy · Band-like alopecia • Linear scleroderma

\section{Abstract}

En coup de sabre morphea is a clinical variant of morphea, presenting as a linear depressed, atrophic area in the paramedian forehead or the frontoparietal scalp, resembling a stroke from a sword. It affects the skin and subcutaneous connective tissues, with possible extension to the underlying musculature, cartilage, and bone and variable association with neurologic symptoms. A 50-year-old woman pre- sented to our clinic for evaluation of an atrophic lesion on her forehead and scalp appearing 1 year before, progressively extending over time. An alopecic atrophic area involving the skin and subcutaneous tissues of her right forehead and scalp arranged in a linear fashion with an "en coup de sabre" appearance was observed in relation with hair loss in the affected area. Reflectance confocal microscopy showed marked hyperreflective areas with severe eccrine gland atrophy. All sebaceous glands had disappeared, with sporadic follicular persistence reduction. Histopathological examination of a punch biopsy specimen taken from a central parietal alopecic area was consistent with a diagnosis of morphea. To our knowledge, this is the first report regarding the karger@karger.com www.karger.com/sad

(C) 2020 S. Karger AG, Base

Karger!
Sara Mazzilli

Department of Dermatology, Tor Vergata University Oxford Street 81

IT-00183 Rome (Italy)

saramazzilli2@gmail.com 
use of reflectance confocal microscopy as an ancillary diagnostic technique in linear localized morphea of the scalp and face. This noninvasive technique may represent a useful tool in distinguishing between early stages of the disease, with prevalence of inflammatory lymphocytic infiltrate, and late stages characterized by more prominent sclerosis with mild or absent signs of inflammation.

(c) 2020 S. Karger AG, Basel

\section{Introduction}

En coup de sabre (ECDS) morphea is a clinical variant of morphea, presenting as a linear depressed, atrophic area in the paramedian forehead or the frontoparietal scalp, resembling a stroke from a sword [1]. It affects the skin and subcutaneous connective tissues, with possible extension to the underlying musculature, cartilage, and bone, and it has variable association with neurologic symptoms [1]. Loss of adnexal structure due to prominent sclerosis of the dermis is characteristic and is most typical of late stages [2]. The inflammatory, fibrosing process results in a nonspecific scarring alopecia. The condition is more common in women and is associated with a higher rate of autoimmune disorders; thus, a complete clinical assessment is recommended [1]. Diagnosis relies on clinicopathological examination. Histopathological features vary, ranging from pictures of sparse perivascular inflammatory infiltrate with mild or absent fibrosis to pictures characterized by prominent sclerosis with no inflammation [2].

\section{Case Report/Case Presentation}

A 50-year-old woman presented to our Clinic for evaluation of an alopecic patch on her scalp appearing 1 year before on the right side of the forehead, progressively expanding over time. Dermatological examination revealed an ivory-colored, atrophic, and indurated hairless area involving her scalp and forehead, arranged in a linear fashion with an "en coup de sabre" appearance. On her right forehead, atrophy of the subcutaneous tissues and bone recess with facial dysmorphia were observed. Personal history included positivity for antinuclear antibodies for many years. Family history reported a case of death for severe systemic sclerosis (Fig. 1-2).

We performed reflectance confocal microscopy (RCM) on an alopecic area of the scalp before performing a punch biopsy of the lesion.

Histopathological examination of a punch biopsy specimen taken from a central parietal alopecic area revealed thickened collagen bundles infiltrating the entire dermis extending into the subcutaneous fat with mild perivascular and focal interstitial lymphocytic infiltrate. Atrophy of sebaceous glands and follicular remnants consistent with an end-stage alopecia were also observed. A diagnosis of late ECDS morphea was made (Fig. 3).

RCM mosaic showed marked hyperreflective areas with severe eccrine gland atrophy. All sebaceous glands had disappeared, with the persistence of sporadic, reduced in size follicles (Fig. 4).

The patient underwent a complete panel of blood and instrumental tests, ruling out a systemic autoimmune condition. Treatment with methotrexate $7.5 \mathrm{mg} /$ week was prescribed.

\section{Discussion}

Morphea is a fibrosing condition limited to the skin, subcutaneous tissues, and underlying bone. Involvement of the central nervous system is rare in relation to the face
1

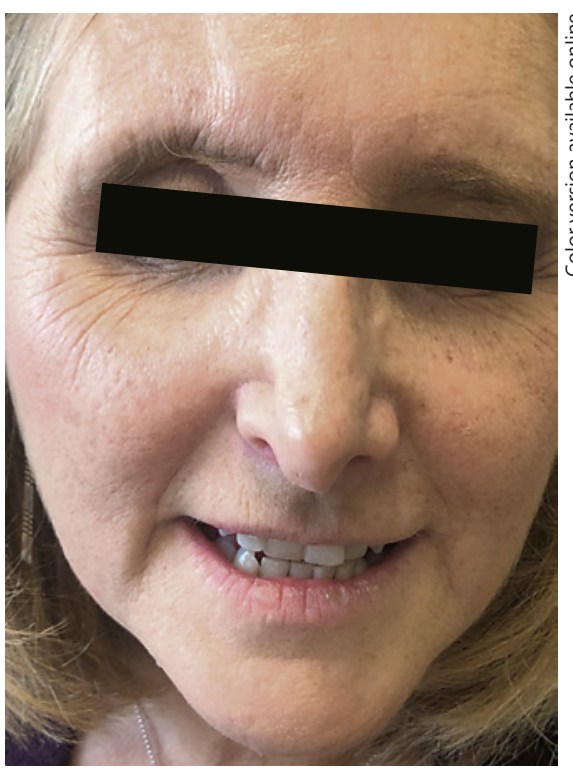

2

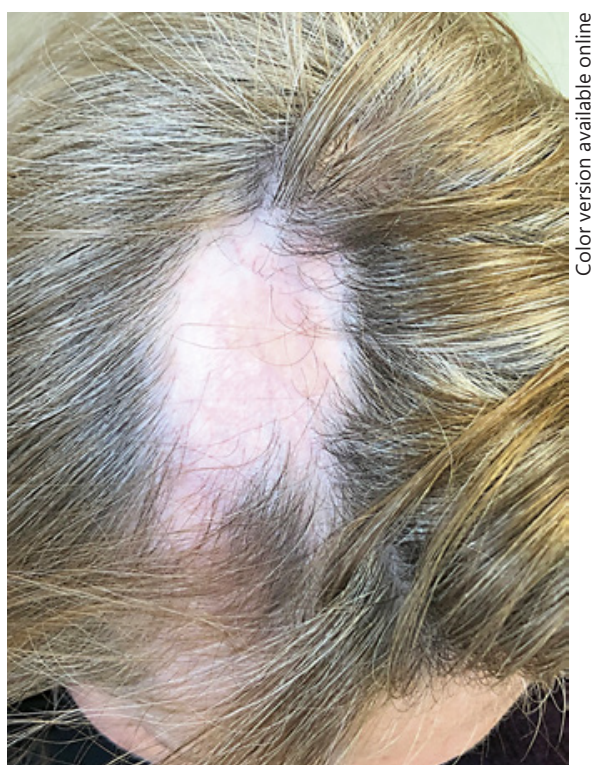

Fig. 1. Clinical image of coup de sabre atrophy of patient's face.

Fig. 2. Clinical image of linear alopecia.
Skin Appendage Disord 2020;6:171-174 DOI: $10.1159 / 000506748$
Mazzilli/Vollono/Cosio/Donati/Piccolo/ Di Raimondo/Campione/Bianchi 
and head area localization [1]. Ocular involvement may be asymptomatic; thus, regular ophthalmologic examinations are recommended for children with head and neck morphea [3]. Young females (mean age 13.6 years) are most commonly affected, and more likely to have a family history of autoimmunity [4].

ECDS morphea indicates a peculiar clinical presentation, characterized by an atrophic, indurated area on the paramedian forehead or the frontoparietal scalp, resembling a stroke from a sword. Although very typical, a sim-

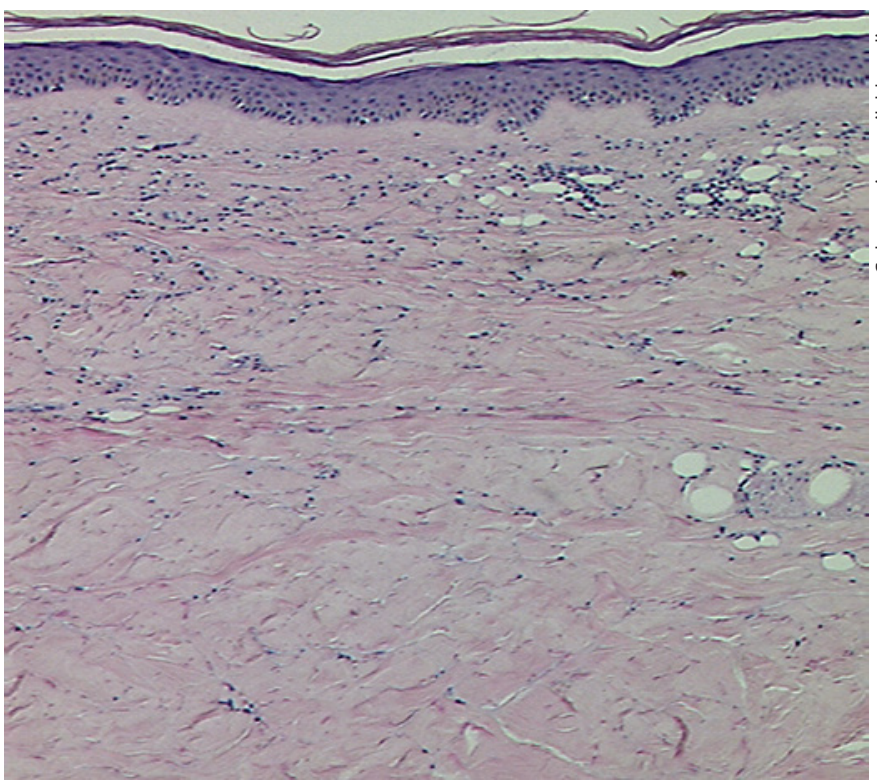

Fig. 3. Histopathological examination of a punch biopsy specimen taken from the central zone of the linear parietal alopecia revealed thickened collagen bundles infiltrating the entire dermis extending into the subcutaneous fat with mild perivascular and focal interstitial lymphocytic infiltrate. Atrophy of sebaceous glands and follicular remnants consistent with an end-stage alopecia were also observed. A diagnosis of late "en coup de sabre" morphea was made. ilar clinical presentation could be observed in discoid lupus erythematosus, linear lichen sclerosus, and linear alopecia areata [5-8]. Diagnosis is based on histology; however, specific dermoscopic features have been identified, suggesting a role for noninvasive tool in diagnosis and management of morphea and lichen sclerosus [9]. No studies regarding the use of RCM in ECDS morphea have been published to date.

In our case, RCM described marked hyperreflective areas with severe eccrine gland atrophy. All sebaceous glands had disappeared, with sporadic follicular persistence reduction (Fig. 3).

These atrophic follicular remnants could be related to telogen follicles but were microscopically different. The morphology of these persistent follicles suggested an endstage alopecia.

We believe that in cases of scarring alopecia, including morphea or connective tissue disorders, especially in early stages, RCM could represent a useful second-line diagnostic and therapeutic tool avoiding unnecessary biopsies.

\section{Conclusion}

To our knowledge, this is the first report regarding the use of RCM as an ancillary diagnostic technique in linear localized morphea of the scalp and face. This noninvasive tool may represent a useful method for distinguishing between early stages of the disease, with prevalence of inflammatory lymphocytic infiltrate, and late stages characterized by more prominent sclerosis with mild or absent signs of inflammation.

Further studies are needed to evaluate the usefulness of RCM in the diagnosis and therapy management of hair disorders.
Fig. 4. RCM mosaic shows marked hyperreflective areas with severe eccrine gland atrophy (blue circle). All sebaceous glands disappeared, with the persistence of sporadic, reduced in size follicles (red circles).

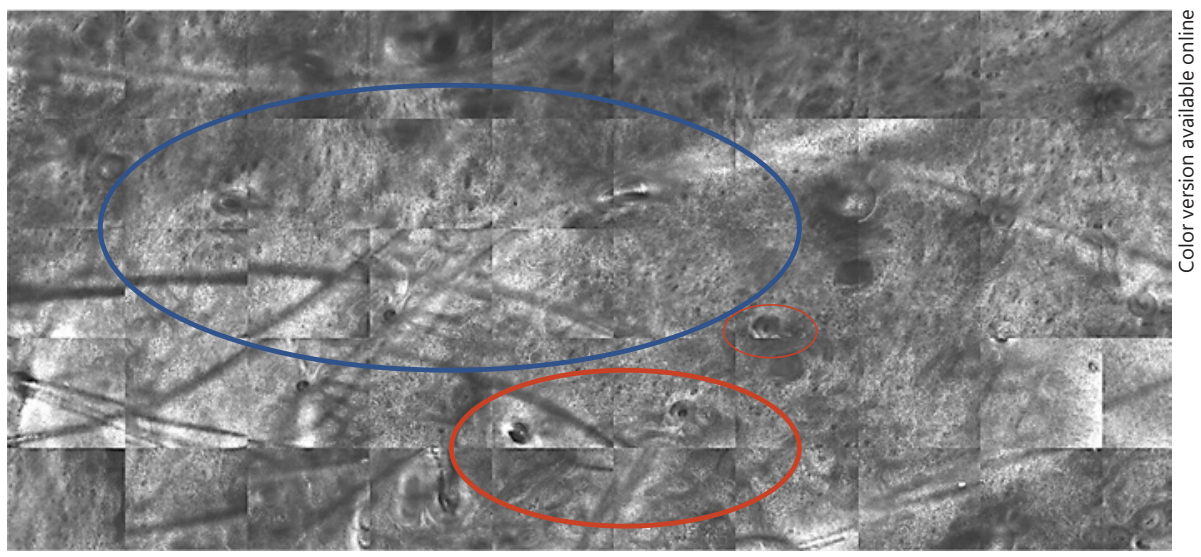

The Usefulness of RCM in the Diagnosis of Cicatricial Alopecia
Skin Appendage Disord 2020;6:171-174 DOI: $10.1159 / 000506748$ 


\section{Statement of Ethics}

The authors declare that the subject has given her written informed consent to publish her case (including publication of images).

\section{Disclosure Statement}

All authors have not conflict of interest.

\section{Author Contributions}

Each author has (1) made substantial contributions to the conception or design of the work, or to the acquisition, analysis, or interpretation of data for the work; (2) participated in drafting the work or revising it critically for important intellectual content; (3) approved the final version to be published; (4) agreed to be accountable for all aspects of the work in ensuring that questions related to the accuracy or integrity of any part of the work are appropriately investigated and resolved.

\section{Funding Sources}

None.

\section{References}

1 Fett N, Werth VP. Update on morphea: part I. Epidemiology, clinical presentation, and pathogenesis. J Am Acad Dermatol. 2011 Feb; 64(2):217-28.

2 Rongioletti F, Ferreli C, Atzori L, Bottoni U, Soda G. Scleroderma with an update about clinico-pathological correlation. G Ital Dermatol Venereol. 2018 Apr;153(2):208-15.

3 Zulian F, Athreya BH, Laxer R, Nelson AM, Feitosa de Oliveira SK, Punaro MG, et al.; Juvenile Scleroderma Working Group of the Pediatric Rheumatology European Society (PRES). Juvenile localized scleroderma: clinical and epidemiological features in 750 children. An international study. Rheumatology (Oxford). 2006 May;45(5):614-20.
4 Tollefson MM, Witman PM. En coup de sabre morphea and Parry-Romberg syndrome: a retrospective review of 54 patients. J Am Acad Dermatol. 2007 Feb;56(2):257-63.

5 Sindhusen S, Chanprapaph K, Rutnin S. Adult-onset linear discoid lupus erythematosus on the forehead mimicking en coup de sabre: A case report. J Med Case Rep 2019 Nov; 13(1):350.

6 Sonthalia S, Agrawal M, Sharma P, Goldust $M$. Linear patch of alopecia in a child: trichoscopy reveals the actual diagnosis. Skin Appendage Disord. 2019 Nov;5(6):409-12.
7 Nam KH, Park SW, Kwak HB, Jung ES, Lee SK, Yun SK. Linear facial lichen sclerosus mimicking scleroderma 'en coup de sabre'. Eur J Dermatol. 2019 Dec;29(6):661-2.

8 Hassan M, Watters KA, Netchiporouk E. Linear discoid lupus erythematosus mimicking en coup de sabre morphea: A case report. SAGE Open Med Case Rep. 2019 Oct; 7: $2050313 X 19882843$.

9 Errichetti E, Lallas A, Apalla Z, Di Stefani A, Stinco G. Dermoscopy of Morphea and Cutaneous Lichen Sclerosus: Clinicopathological Correlation Study and Comparative Analysis. Dermatology. 2017;233(6):462-70. 